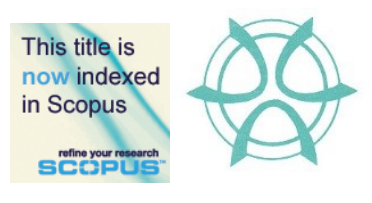

PLANNING MALAYSIA:

Journal of the Malaysian Institute of Planners

VOLUME 19 ISSUE 1 (2021), Page 138 - 149

\title{
QUALITY OF DESIGNS AND FEATURES OF SMALL URBAN GREEN SPACES IN PETALING JAYA TOWN, MALAYSIA
}

\author{
A.A. Fatiah ${ }^{1}$, Zakiah Ponrahono ${ }^{2}$, Khalilah Zakariya ${ }^{3}$, \\ ${ }^{1,2}$ Faculty of Forestry and Environment, \\ UNIVERSITI PUTRA MALAYSIA \\ ${ }^{3}$ Kulliyyah of Architecture and Environmental Design, \\ INTERNATIONAL ISLAMIC UNIVERSITY MALAYSIA
}

\begin{abstract}
Small Urban Green Spaces (SUGS) mushroomed in dense cities as a scaleddown version of larger parks. In the past, SUGS are often abandoned, or their quality is often overlooked. The purpose of this study is to explore the design and features to make a good quality SUGS. Five experts were approached with a weightage evaluation to rate its quality based on selected criteria's; Accessibility, Attractiveness, Functionality, and Safety. Each criterion had a variable to measure the construct. Findings from the expert evaluation showed that SUGS were rated medium or low overall quality. The variables that obtained the highest score and attained high-quality ratings were Obstacles (Safety criteria), General Maintenance (Attractiveness criteria), and Play Area (Accessibility criteria). Interview with park users revealed that they preferred the "presence of trees," "well-maintained environment," and "walking path accessibility." The least preferred attributes were "poor maintenance," "dangerous walking path," and "negative perception of safety." Overall, to ensure the quality of SUGS attention should be placed on the Accessibility of its features (e.g., walking path and play area), the attractiveness of the park (e.g., vegetation and maintenance), the functionality of the features (e.g., sports facilities) and perception of Safety (e.g., absence of obstacles).
\end{abstract}

Keywords: Attractive; Accessible; Functional; Safe; Neighbourhood Parks; Park Users

\footnotetext{
${ }^{2}$ Corresponding Author. Email: zakh@upm.edu.my
} 
PLANNING MALAYSIA

Journal of the Malaysia Institute of Planners (2021)

\section{INTRODUCTION}

Urbanisation has caused a significant decline in green spaces, which impacts the well-being of city dwellers because it goes against the natural tendency of people to connect with the natural environment for psychological restoration (Nordh, Hartig, Hagerhall, \& Fry, 2009). Open space in the form of Small Urban Green Spaces (SUGS) is found in cities and towns with limited space (Nordh and Østby (2013). SUGS placed within communities allows residents to connect with nature while fostering an area to carry out a range of activities, whether it is passive or active. The UGS system hierarchy starts from local, district to city levels, where parks in residential areas are the SUGS provided right at users' doorsteps. SUGS are scaled-down versions of larger parks, where some vegetation is present.

\section{Experience Factors of Green Spaces}

The quality of green space is judged based on various attributes such as specific facilities and amenities, fitness for use, and maintenance. Malek et al. (2012) defined the quality of green spaces as a space that fits the users' needs. This study identified four criteria to measure the quality of SUGS subjectively. The first factor, Accessibility, is evaluated based on its welcoming atmosphere or the spatial ease in reaching the activities available because it is essential for usability and functionality. Attractiveness encourages users to spend time in the space willingly. Studies have shown that users prefer the presence of biodiversity and natural features (e.g. trees, brightly coloured flowers and birds), attractive amenities (e.g. park furniture and leisure equipment's) and a clean and wellmaintained environment (Biernacka \& Kronenberg, 2018; Wen, Albert, \& Von Haaren, 2018). Functionality, however, is the way green spaces are perceived and used by users. This relates to the variety of features and facilities provided, where users form an attachment with the space according to how they function in it (Stessens et al., 2017). The last factor is Safety, where it can either be judged objectively (by experience) or subjectively (by perception) (Maas et al., 2009).

\section{Significance of the Study}

Green spaces come in different shapes and forms, but they should be designed with quality to give benefits to their users (Aram, Solgi, \& Holden, 2019). SUGS in residential areas is still not fully utilised or even abandoned despite being a fundamental social space in city planning (Anuar \& Muhamadan, 2018; Moulay, Ujang, \& Said, 2017). Thus, this study aims to add to the body of knowledge and qualitatively assess the quality of designs and features of SUGS that are meant for rest and recreation to understand the factors that are perceived to make a good quality space. On that basis, the main objectives of this paper are:

(1) To determine the main designs and features of Small Urban Green Spaces

(2) To assess the quality of designs and features of Small Urban Green Spaces 
Fatiah, A.A, Ponrahono, Z. \& Zakariya, K.

Quality of Designs and Features of Small Urban Green Spaces in Petaling Jaya Town, Malaysia

Therefore, the questions addressed in this study are:

(1) What are the typical size, layout, and concept of Small Urban Green Spaces?

(2) What is the quality of current Small Urban Green Spaces?

\section{METHODOLOGY}

\section{Study Area}

The primary data collection was carried out from January to February 2019 in six (6) selected Small Urban Green Space (SUGS) in Petaling Jaya (PJ), Selangor, Malaysia. The secondary data collection was carried out in March 2019. Selected SUGS are under the jurisdiction of Petaling Jaya City Council (PJCC), where the administrative area consists of 97.2 square kilometres. The parks were selected based on criteria for size, location, and function (Jasmani, Ravn, \& van den Bosch, 2017) using the earth observation technique by Google Earth (Refer to Figure 1). The size of the selected SUGS for this study was between 0.2 to 2 ha.

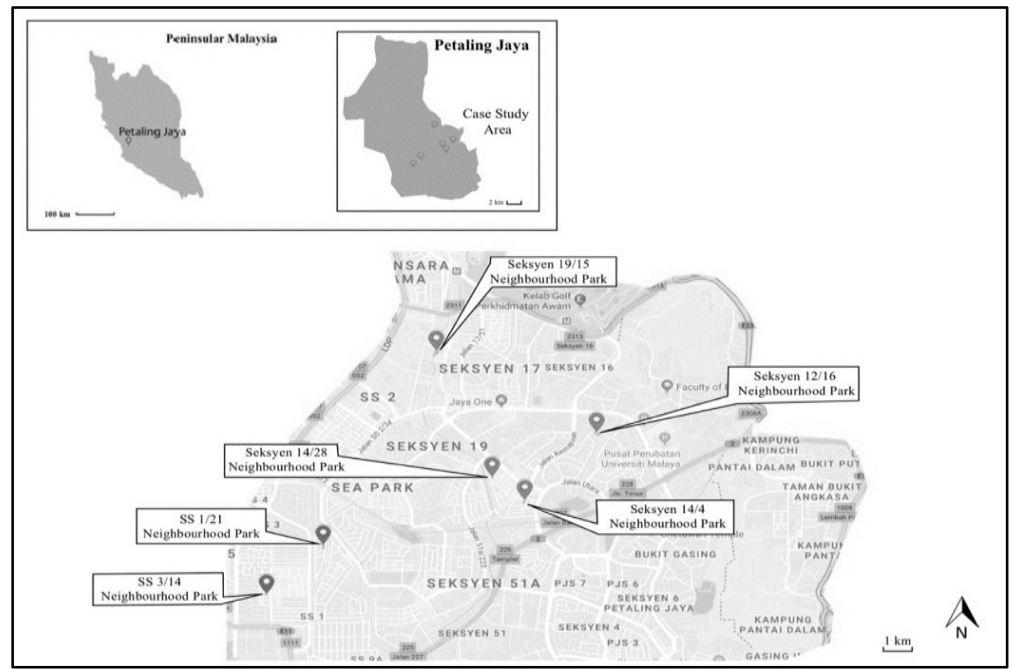

Figure 1: Selected SUGS in PJ (This map was extracted from Google Earth satellite image)

\section{Primary Data Collection}

To meet the first objective, an inventory, photographic stimuli, and layout were obtained for each SUGS. A joint structured observation and field measurement method was used to look at the characteristics of the park. Field measurements were carried out to map the routes and waypoints of the park's shape, walking path, facilities, and furniture using a Garmin Geographical Positioning System 64s device. Photographic stimuli were then obtained using a 
high-resolution camera. The photographs were taken at eye level on clear or less cloudy days using panoramic views to reflect all the area's characteristics. The data collected from the inventory, layout, and photographic stimuli are used as tools for experts to carry out weightage evaluation.

\section{Secondary Data Collection}

Experts and park users were approached to objectively and subjectively evaluate the quality of design and features in SUGS.

\section{Variables and Measures for Quality Weightage Evaluation}

For the weightage evaluation, a systematic literature review technique was used to establish variables and items. Table 1 shows the criteria with the variables used to measure subjective quality. There were 14 variables in total, as listed in Table 1 ; each had a subjective statement to measure the construct.

Table 1. Criteria for Quality Assessment with selected Variables

\begin{tabular}{ll}
\hline \multicolumn{1}{c}{ Criteria } & \multicolumn{1}{c}{ Variables } \\
\hline Accessibility & Walking Path (WP), Play Area (PA), Shelter/Shade (SS), and Furniture \\
& (F). \\
Attractiveness & Shelter/Shade (SS), Vegetation (V), General Maintenance (GM), and \\
& General Naturalness (GN). \\
Functionality & Sports Facilities (SP), Seating (S) and Vegetation (V). \\
Safety & Boundary (B), Obstacles (O) and Lighting (L). \\
\hline
\end{tabular}

\section{Expert Judgment for Quality Weightage Evaluation}

Once the items were established, experts were approached. Previous studies on the expert-based judgment of landscape are often used between four to nine experts (Wang, Zhao, \& Liu, 2016; Bakar, Malek, \& Mansor, 2016). Five experts were approached to meet the second objective; a weightage evaluation was provided to experts to evaluate the quality based on selected park criteria objectively. The weightage was rated by experts in the field of environmental planning and design from a governmental sector and educational institutes. The scoring technique used was according to a study done by (Malek, Mariapan, \& Shariff, 2012) and (Bakar, Malek, \& Mansor, 2016) on the Quality of Neighbourhood Park Criteria (QNPC) (Refer to Table 2).

Table 2. Quality of SUGS Classification (Source: QNPC Scoring Marks as derived from (Bakar, Malek, \& Mansor, 2016; Malek, Mariapan, \& Shariff, 2012)

\begin{tabular}{cc}
\hline \multicolumn{2}{c}{ QNPC Scoring Marks } \\
\hline $\mathbf{0 - 5 9}$ & Low \\
$\mathbf{6 0 - 7 9}$ & Medium \\
$\mathbf{8 0 - 1 0 0}$ & High \\
\hline
\end{tabular}

\section{Interview with Park Users}

To further achieve the second objective, park users were interviewed to evaluate park quality subjectively. A semi-structured interview with park users carried out 
Fatiah, A.A, Ponrahono, Z. \& Zakariya, K.

Quality of Designs and Features of Small Urban Green Spaces in Petaling Jaya Town, Malaysia

with an open-ended question on which attributes of the park they favoured the most and the ones they least favoured as a source of qualitative data. A random sampling approach is adopted for users, where every five to six individuals that visit the selected park were approached. Thus, a total of 41 park users were interviewed. The selected park users were those using the facilities (e.g., using the equipment or walking path, sitting on the bench or gazebo), while those who were merely using the park as a short cut were not approached. The interview session was conducted in each park for two days, one on a weekday and the weekend in the morning (7.30-9.00 am) and evening (5.30-7.00 pm) between February 2019 to April 2019.

\section{Data analysis}

The data were compiled in Microsoft Excel and transferred to SPSS, where the average QNPC marks (refer to Table 2) were used to classify the average scores of variables, criteria, and overall quality from scores (refer to equations in appendix H) based on expert evaluation. The average score was classified based on low, medium, or high quality using the QNPC scores. Next, Spearman's correlation was used to test the strength of the relationship between the four criteria (Accessibility, Attractiveness, Functionality, and Safety) and the Overall Quality based on the QNPC scores.

\section{FINDINGS}

\section{Expert Evaluation on Variables for Quality}

Table 3 depicts the average scores for the variables based on expert evaluation for each park. The variables that obtained the highest score and attained highquality ratings were O (Safety criteria), GM (Attractiveness criteria), and PA (Accessibility criteria). On the other hand, the variables that obtained the lowest score and had obtained low-quality ratings were GN (Attractiveness criteria), S (Functionality criteria), SS (Accessibility and Attractiveness criteria), and L (Safety criteria)

\section{Expert evaluation of Criteria for Quality and Overall Quality}

Based on the expert weightage evaluation, the scores of the parks' average scores were quantified to obtain the mean for criteria of Accessibility, Attractiveness, Functionality, and Safety. Then, the criteria were classified based on the QNPC marks, as shown in Table 4. SS 3/14 and Seksyen 14/28 parks were rated lowquality with scores of $56 \%$ and $55 \%$, respectively. The highest score was attained by Seksyen 19/15 park, and the lowest score was obtained by Seksyen 14/28 park. All the criteria (Attractiveness, Accessibility, Functionality, and Safety) were at low or medium quality, ranging from $50 \%$ to $75 \%$. 


\section{Relationship between Criteria for Quality and Overall Quality}

A very strong relationship was observed between the Overall Quality for Accessibility (AC) (0.896), Attractiveness (AT) (0.862), and Functionality (FN) $(0.820)$ criteria. On the other hand, Safety $(0.329)$ depicted a weak relationship with Overall Quality. AC showed a strong relationship with AT and FN (AC-AT $=0.618 ; \mathrm{AC}-\mathrm{FN}=0.763$ ) but AT showed a moderate relationship with FN (AT$\mathrm{FN}=0.553$ ). SA was an exception as it showed a weak relationship with $\mathrm{AC}$ and AT $($ AC-SA $=0.316$; AT-SA $=0.135)$ and an even weaker relationship with FN $(\mathrm{FN}-\mathrm{SA}=0.178)$. Table 6 depicts the correlation coefficients of the criteria.

\section{Park Users Perception}

According to interviews with park users, the most preferred and the least preferred attributes based on the design and features in a park are shown in Figure 4 and Figure 5. The most preferred park attributes were the "presence of trees", followed by "clean and well-maintained environment", and "easy access of walking path". The attributes that park users preferred the least were the perception of the "lack of maintenance", followed by the "dangerous walking path" and the "negative perception of safety".

Table 3: Average QNPC Scores of Variable

\begin{tabular}{|c|c|c|c|c|c|c|c|c|}
\hline Variables & Criteria & $\begin{array}{l}\text { Sek. } \\
12 / 16\end{array}$ & $\begin{array}{l}\text { Sek. } \\
14 / 4\end{array}$ & $\begin{array}{l}\text { Sek. } \\
14 / 28\end{array}$ & $\begin{array}{l}\text { Sek. } \\
19 / 15\end{array}$ & $\begin{array}{l}\text { SS } \\
1 / 21\end{array}$ & $\begin{array}{l}\text { SS } \\
3 / 14 \\
\end{array}$ & $\begin{array}{l}\text { Average } \\
\text { Score }\end{array}$ \\
\hline Obstacles (O) & Safety & 84 & 76 & 72 & 84 & 92 & 68 & 79 \\
\hline General & & & & & & & & \\
\hline $\begin{array}{l}\text { Maintenance } \\
(\mathrm{GM})\end{array}$ & Attractiveness & 68 & 84 & 68 & 92 & 68 & 68 & 75 \\
\hline $\begin{array}{l}\text { Play Areas } \\
\text { (PA) }\end{array}$ & Accessibility & 60 & 68 & 64 & 84 & 84 & 76 & 73 \\
\hline Sports (SP) & Functionality & 56 & 60 & 64 & 84 & 92 & 68 & 71 \\
\hline $\begin{array}{l}\text { Walking Path } \\
\text { (WP) }\end{array}$ & Accessibility & 60 & 76 & 72 & 76 & 76 & 52 & 69 \\
\hline Boundary (B) & Safety & 64 & 72 & 60 & 80 & 72 & 60 & 68 \\
\hline $\begin{array}{l}\text { Vegetation } \\
\text { (V) }\end{array}$ & $\begin{array}{l}\text { Attractiveness } \\
\text { and } \\
\text { Functionality }\end{array}$ & 71 & 75 & 52 & 79 & 64 & 63 & 67 \\
\hline Furniture $(\mathrm{F})$ & Accessibility & 68 & 76 & 60 & 60 & 68 & 44 & 63 \\
\hline $\begin{array}{l}\text { General } \\
\text { Naturalness } \\
(\mathrm{GN})\end{array}$ & Attractiveness & 60 & 68 & 44 & 64 & 60 & 48 & 57 \\
\hline Seating (S) & Functionality & 64 & 66 & 44 & 60 & 56 & 48 & 56 \\
\hline $\begin{array}{l}\text { Shelter/Shade } \\
\text { (SS) }\end{array}$ & $\begin{array}{l}\text { Accessibility } \\
\text { and } \\
\text { Attractiveness }\end{array}$ & 64 & 66 & 44 & 60 & 56 & 48 & 56 \\
\hline Lighting (L) & Safety & 44 & 40 & 40 & 56 & 48 & 40 & 45 \\
\hline & Legend & & \multicolumn{2}{|c|}{ High-Quality } & \multicolumn{2}{|c|}{ Medium-Quality } & \multicolumn{2}{|c|}{ Low-Quality } \\
\hline
\end{tabular}


Fatiah, A.A, Ponrahono, Z. \& Zakariya, $K$.

Quality of Designs and Features of Small Urban Green Spaces in Petaling Jaya Town, Malaysia

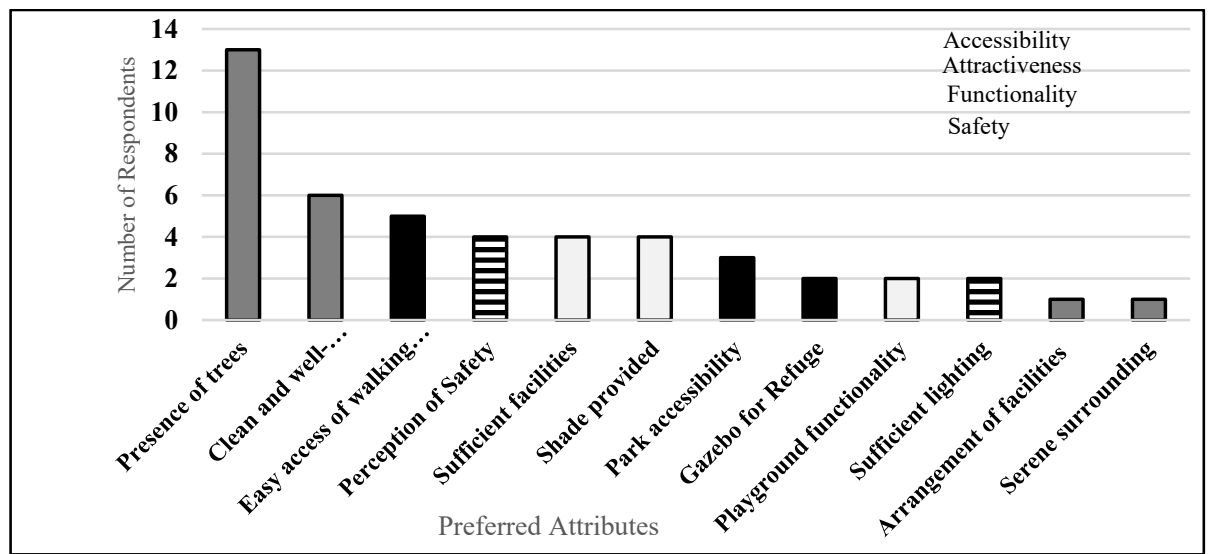

Figure 4: The attributes that park users preferred with the characteristics of quality (Accessibility, Attractiveness, Functionality and Safety)

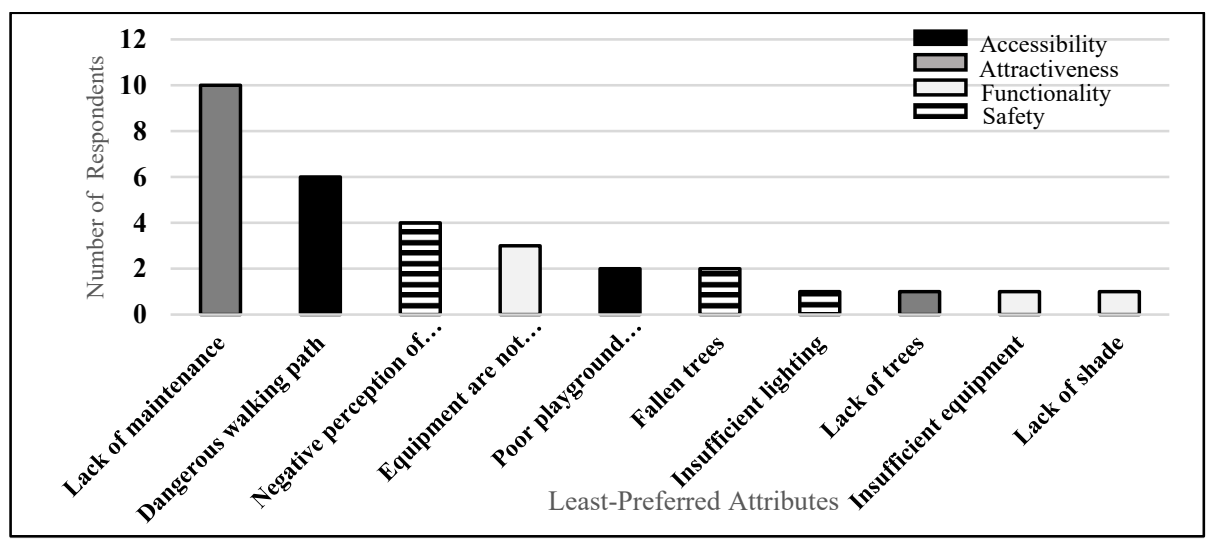

Figure 5. The least preferred park attributes by users with the characteristics of quality (Accessibility, Attractiveness, Functionality and Safety)

\section{DISCUSSION}

This study aims to measure quality based on four pre-requisite criteria (Accessibility, Attractiveness, Functionality, and Safety) to draw on variables that should be given attention and identify the weak variables that need improvement. There have been several noteworthy findings from this regarding the quality of SUGS.

\section{Quality of Neighbourhood Parks based on Expert-Based Judgment}

The findings show that experts perceive that SUGS does not meet high-quality standards. Although one of the selected parks, Seksyen 19/15 park, obtained the highest score for the overall quality. We used this park as an ideal space to identify successful features that contributed to its high rating of quality. First, the 
criteria that obtained the highest score for the quality measure in Seksyen 19/15 park was Functionality and Safety. The variable to measure Functionality, Sports Facilities, was rated high-quality for Seksyen 19/15 park. This park provided space for a basketball court and various equipment suitable for users of various age groups; this shows that SUGS that offers active recreation opportunities contributes to a good quality park. The findings are in line with a study by Cohen et al. (2014), which found that parks in residential areas that are equipped with various facilities promote physical activity where park use is determined by the presence of basketball courts, tennis courts, and exercise facilities.

On the other hand, the variables Boundary and Obstacle used to measure Safety criteria were rated high-quality for Seksyen 19/15 park. These two variables were drawn from the Safe Community Principles by Luymes and Tamminga (1995), where variable B refers to the ability to see others in the space visibly. While the variable $\mathrm{O}$ refers to the visibility by others, which is the ability to be seen when within the space, which could invoke a sense of Safety. The highquality rating for variable $\mathrm{O}$ reflects experts' perception that the space does not have any perceived obstruction of view. Thus, it is essential to avoid placing any components in SUGS that block users from looking around the space. As stated by Hadavi, Kaplan, and Hunter (2018), any perceived barriers in green spaces create a safety concern due to a negative association of it by park users. Next, Variable B's high-quality rating shows that a distinct boundary is a crucial component to determine the quality of SUGS. A distinct boundary or a welldefined area is vital for SUGS as separation from the surrounding space (Nordh et al., 2009; Peschardt et al., 2012). Thus, designing parks with access mechanisms through property controls such as the barriers can regulate entry, which is a crime prevention feature (Iqbal \& Ceccato, 2016).

To identify factors that should be improved; we also looked at the parks with the lowest ratings to learn from features that require improvement in these SUGS. The parks that obtained an overall low quality were Seksyen 14/28 and SS $3 / 14$ park. Both of these parks obtained a low-quality rating for the variables General Naturalness (GN), Seating (S), Shelter/Shade (SS), and Lighting (L) by experts. Firstly, S variable as a measure for the functionality criteria shows SUGS with poor seating arrangement, and even the lack of seating reflects a low-quality space. Benches are essential features in SUGS, where studies by Nordh et al. (2009) and Peschardt and Stigsdotter (2013) found that benches draw attention to SUGS because they give the space a sense of "refuge."

Moreover, apart from providing benches, Peschardt and Stigsdotter (2014) mentioned that the placement should also be given importance where benches should provide a visual view that should not be directed to disturbing surroundings. These parks obtained a low-quality rating for the SS variable, which is the variable for attractiveness and accessibility criteria. The low-quality rating is a distinctive feature that these two parks did not provide, a gazebo or a 
Fatiah, A.A, Ponrahono, Z. \& Zakariya, K.

Quality of Designs and Features of Small Urban Green Spaces in Petaling Jaya Town, Malaysia

shaded area for rainy days. In Malaysia's tropical climate (hot and humid with rain throughout the year), a place of refuge is an essential provision in a green space. SUGS should provide a shaded area to create a rest and restitution space for the park users (Peschardt \& Stigsdotter, 2014).

Moreover, green spaces need to have natural features present than built features. Hence, the GN variable's low-quality rating reflects that experts perceived them to have a poor ratio of natural features to built features. The $\mathrm{L}$ variable for all the parks obtained a low-quality rating. The parks were perceived to have poor quality because of the insufficiency of lighting provided. A study by Ngesan, Karim, and Zubir (2012) stated that the presence of artificial lights positioned strategically provides visibility and protection and is vital to increase night-time use for leisure and recreational activities.

\section{Perception of Park Users on Small Urban Green Space Design and Features}

Results showed that park users' most preferred attribute in SUGS was the "presence of trees". A study by (Malek \& Nashar, 2018) reported similar findings on their green space design in Malaysian parks, where the author found that "nature appreciation" is the most valued feature. Meanwhile, Nordh et al. (2009) elaborated that users prefer the presence of natural features in SUGS because they give a sense of mental restoration, a sense of recovery from mental fatigue. One of the park users also mentioned that trees are suitable for shade, but placing trees in the wrong place can create a sense of insecurity in the space. Additionally, "a clean and well-maintained environment" was an attribute preferred by users, while the least preferred park attribute was "the lack of maintenance" in the parks. A study by Danis et al. (2014) stated that trash and general uncleanliness reduce aesthetic quality and deter use. Maintenance refers to the fallen dried vegetation around the park. People interpret well-maintained lawns in green spaces as a sign of care that makes the place looks safer (Akpinar, 2016). Although this factor relates more to social factors and management than the design or facilities, it is still essential in representing the space's attractiveness.

Park users also prefer easy Accessibility of the walking path. Pathways accessible and connected will draw a large number of users (Zhai \& Baran, 2016). Although "dangerous walking path" was highlighted as one of the least preferred attributes, users added that the walking path is not safe for elderly people due to its uneven surfaces, and at times, after it rains, the path becomes slippery. Zhai and Baran (2017) found that pathways with smooth pavement fit seniors with limited movement the most, where brick or plastic pavements attract more senior users while uneven ones deter use.

Users in some of the selected parks mentioned that "negative perception of safety" was the least preferred attribute in the SUGS; this shows that perception of Safety is one of the main determining factors of park use. Perceived Safety is how safe people perceive a place is or the feelings of Safety it invokes, where it 
can be affected by factors such as the lighting and views of other users (Bakar et al., 2016). Perceived Safety can be affected by various factors such as the placement of trees, lighting for park usage at night and a well-defined boundary. (Malek \& Nashar, 2018) elaborated that too many trees can reduce a user's visual link, which creates a sense of enclosure. Meanwhile, Iqbal and Ceccato (2016) explained that perceived safety is reflected in physical design for users to navigate through space with features such as proper barriers, enclosures, and entry points.

\section{RECOMMENDATIONS AND CONCLUSIONS}

The findings of this study contributed to an improved understanding of the perceived quality of SUGS. Each park is different and unique; thus, it is a challenge to create one standard that could assess the quality of design and facilities in all SUGS. SUGS in Malaysia is often designed to conform to a standard where its quality can be easily overlooked or neglected. Based on the expert evaluation findings, scores showed that most of the SUGS in PJ fell within a medium or low overall quality. Park users stressed on the Accessibility of the walking path and maintenance. This study recommends that the managers (i.e. local authority) and designers of SUGS provide quality in terms of better Accessibility to its features, such as the walking path and play area. Next, the attractiveness of the park should be improved with better planning on vegetation density and location.

\section{ACKNOWLEDGEMENTS}

This research was fully supported by Geran Inisiatif Putra Siswazah (GPIPS/2021/9698800.

\section{REFERENCES}

Akpinar, A. (2016). How is quality of urban green spaces associated with physical activity and health? Urban forestry \& urban greening, 16, 76-83.

Anuar, a. N. A., \& muhamadan, n. H. (2018). The demand of recreational facilities in neighbourhood parks: visitors'perspectives. Planning malaysia journal, 16(7).

Aram, F., Solgi, E., \& Holden, G. (2019). The role of green spaces in increasing social interactions in neighborhoods with periodic markets. Habitat International, 84, 24-32.

Bakar, N. A., Malek, N. A., \& Mansor, M. (2016). Access to Parks and Recreational Opportunities in Urban Low-income Neighbourhood. Procedia-social and behavioral sciences, 234, 299-308.

Biernacka, M., \& Kronenberg, J. (2018). Classification of institutional barriers affecting the availability, Accessibility and attractiveness of urban green spaces. Urban forestry \& urban greening, 36, 22-33.

Cohen, D. A., Marsh, T., Williamson, S., Han, B., Derose, K. P., Golinelli, D., \& McKenzie, T. L. (2014). The potential for pocket parks to increase physical activity. American journal of health promotion, 28(3_suppl), S19-S26. 
Fatiah, A.A, Ponrahono, Z. \& Zakariya, K.

Quality of Designs and Features of Small Urban Green Spaces in Petaling Jaya Town, Malaysia

Danis, A., Sidek, S., \& Yusof, S. M. (2014). Environmental characteristics influences on physical activity among overweight adolescents: Urban neighbourhood parks. Procedia-social and behavioral sciences, 153, 402-409.

Hadavi, S., Kaplan, R., \& Hunter, M. R. (2018). How does perception of nearby nature affect multiple aspects of neighbourhood satisfaction and use patterns? Landscape Research, 43(3), 360-379.

Iqbal, A., \& Ceccato, V. (2016). Is CPTED useful to guide the inventory of Safety in parks? A study case in Stockholm, Sweden. International criminal justice review, 26(2), 150-168.

Jasmani, Z., Ravn, H. P., \& van den Bosch, C. C. K. (2017). The influence of small urban parks characteristics on bird diversity: A case study of Petaling Jaya, Malaysia. Urban ecosystems, 20(1), 227-243.

Luymes, D. T., \& Tamminga, K. (1995). Integrating public Safety and use into planning urban greenways. Landscape and Urban Planning, 33(1-3), 391-400.

Maas, J., Spreeuwenberg, P., Van Winsum-Westra, M., Verheij, R. A., Vries, S., \& Groenewegen, P. P. (2009). Is green space in the living environment associated with people's feelings of social safety? Environment and Planning A, 41(7), 1763 1777.

Malek, N. A., Mariapan, M., \& Shariff, M. K. M. (2012). The making of a quality neighbourhood park: A path model approach. Procedia-social and behavioral sciences, 49, 202-214.

Malek, N. A., \& Nashar, A. (2018). Use pattern and activities: The evaluation of Malaysian green open space design. PLANNING MALAYSIA Journal of the Malaysian Institute of Planner, 16(7).

Moulay, A., Ujang, N., \& Said, I. (2017). Legibility of neighborhood parks as a predicator for enhanced social interaction towards social sustainability. Cities, 61, 58-64.

Ngesan, M. R., Karim, H. A., \& Zubir, S. S. (2012). Human behaviour and activities in relation to Shah Alam urban park during night-time. Procedia-social and behavioral sciences, 68, 427-438.

Nordh, H., Hartig, T., Hagerhall, C., \& Fry, G. (2009). Components of small urban parks that predict the possibility for restoration. Urban forestry \& urban greening, 8(4), 225-235.

Nordh, H., \& Østby, K. (2013). Pocket parks for people-A study of park design and use. Urban forestry \& urban greening, 12(1), 12-17.

Peschardt, K. K., Schipperijn, J., \& Stigsdotter, U. K. (2012). Use of small public urban green spaces (SPUGS). Urban forestry \& urban greening, 11(3), 235-244.

Peschardt, K. K., \& Stigsdotter, U. K. (2013). Associations between park characteristics and perceived restorativeness of small public urban green spaces. Landscape and Urban Planning, 112, 26-39.

Peschardt, K. K., \& Stigsdotter, U. K. (2014). Evidence for designing health promoting pocket parks. International Journal of Architectural Research: ArchNet-IJAR, 8(3), 149-164.

Stessens, P., Khan, A. Z., Huysmans, M., \& Canters, F. (2017). Analysing urban green space accessibility and quality: A GIS-based model as spatial decision support for urban ecosystem services in Brussels. Ecosystem services, 28, 328-340. 
Wang, R., Zhao, J., \& Liu, Z. (2016). Consensus in visual preferences: The effects of aesthetic quality and landscape types. Urban Forestry \& Urban Greening, 20, 210-217.

Wen, C., Albert, C., \& Von Haaren, C. (2018). The elderly in green spaces: Exploring requirements and preferences concerning nature-based recreation. Sustainable cities and society, 38, 582-593.

Zhai, Y., \& Baran, P. K. (2016). Do configurational attributes matter in context of urban parks? Park pathway configurational attributes and senior walking. Landscape and Urban Planning, 148, 188-202.

Zhai, Y., \& Baran, P. K. (2017). Urban park pathway design characteristics and senior walking behavior. Urban forestry \& urban greening, 21, 60-73.

Received: $16^{\text {th }}$ February 2021. Accepted: $8^{\text {th }}$ May 2021 